\title{
Stillbirth in Iran and associated factors (2014-2016): A population-based study
}

\author{
Narjes Khalili ${ }^{1}$, Mohammad Heidarzadeh ${ }^{2}$, Abbas Habibelahi ${ }^{3}$, Batool Tayefi ${ }^{1}$, Mozhdeh Ramezani ${ }^{1}$, Zahra Rampisheh ${ }^{1}$, \\ Arash Tehrani-Banihashemi ${ }^{1}$, Fariba Mirbaha ${ }^{1}$, Farima Raji ${ }^{3}$, Ebrahim Babaee ${ }^{1}$, Rahim Taghizadeh Asl ${ }^{4}$ \\ Maziar Moradi-Lakeh*1(D), Mohsen Naghavi ${ }^{5}$, Ali H. Mokdad ${ }^{5}$
}

Received: 7 Oct 2019

Published: 25 Apr 2020

\section{Abstract}

Background: Under Every Newborn Action Plan (ENAP), stillbirth rate in every country should be reduced by 12 or fewer per 1000 total births by 2030 . The aims of this study were to determine stillbirth rate at national and subnational levels and to investigate its associated risk factors in Iran.

Methods: Using all data from Iranian Maternal and Neonatal Network (IMaN), we calculated stillbirth rate of Iran from 2014-2016. This network registers information of almost all births across the country. The logistic regression was used to estimate the adjusted odds ratio (aOR) with $95 \%$ confidence intervals (CIs) for stillbirth.

Results: In 2014, still birth rate was 7.40 per 1000 births. In 2015 and 2016, stillbirth rates were 7.22 per 1000 births and 7.63 per 1000 births, respectively. The most important related factors of stillbirth were preterm birth $(\mathrm{aOR}=62.53,95 \% \mathrm{CI} ; 60.77-64.34)$, sexual ambiguity $(\mathrm{aOR}=14.51,95 \% \mathrm{CI} ; 12.76-16.50)$, and post term birth $(\mathrm{aOR}=3.31,95 \% \mathrm{CI} ; 2.66-4.13)$.

Conclusion: Under Every Newborn Action Plan (ENAP), stillbirth rate in every country should be reduced by 12 or fewer per 1000 total births by 2030. Iran has achieved stillbirth target of ENAP at national level. It is important for the health care system to establish and improve specific and focused policies, interventions, and programs for achieving this target even in the most deprived areas.

Keywords: Prevalence, Stillbirth, Risk factor, Iran

Conflicts of Interest: None declared

Funding: This study was funded by Iran University of Medical Sciences, Tehran, Iran.

*This work has been published under CC BY-NC-SA 1.0 license.

Copyright $($ Iran University of Medical Sciences

Cite this article as: Khalili N, Heidarzadeh M, Habibelahi A, Tayefi B, Ramezani M, Rampisheh Z, Tehrani-Banihashemi A, Mirbaha F, Raji F, Babaee E, Taghizadeh Asl R, Moradi-Lakeh M, Naghavi M, Mokdad AH. Stillbirth in Iran and associated factors (2014-2016): A population-based study. Med J Islam Repub Iran. 2020 (25 Apr);34:38. https://doi.org/10.47176/mjiri.34.38

\section{Introduction}

Stillbirth imposes a heavy burden on families and societies, with significant physiological and financial impacts. Stillbirth is an important indicator for quality of prenatal and intrapartum care, socioeconomic conditions and equity

Corresponding author: Dr Maziar Moradi-Lakeh, moradilakeh.m@iums.ac.ir

1. Preventive Medicine and Public Health Research Center, Psychosocial Health Research Institute, Department of Community and Family Medicine, School of Medicine, Iran University of Medical Sciences, Tehran, Iran

2. Department of Pediatrics, Tabriz University of Medical Sciences, Tabriz, Iran

3. Neonatal Health Office, Ministry of Health and Medical Education, Tehran, Iran

4. Maastricht University, CAPHRI, Department of Health Promotion, Maastricht, Netherlands

5. Institute for Health Metrics and Evaluation, University of Washington, Seattle, Washington, USA in the society (1-3).

The incidence of stillbirth in different countries varies significantly and depends on the definition used. A total of 2.6 million (uncertainty range of 2.08 million to 3.79 mil-

\section{$\uparrow$ What is "already known" in this topic:}

Before the implementation of Iranian Maternal and Neonatal Network (IMaN), our estimation of national and provincial stillbirth rate was limited to rural areas and a nonrandom urban subpopulation, without any details on maternal or neonatal conditions.

\section{$\rightarrow$ What this article adds:}

We estimated the average stillbirth rate of 7.42 per 1000 total births during 2014-2016 in Iran. The highest stillbirth rates occurred in the southeast and northwest of the country. Iran has achieved stillbirth target of Every Newborn Action Plan (12 per 1000 total births) at national level. 
lion) women experienced stillbirth in 2015 worldwide, of which 1.3 million occurred during labor and delivery. Also, $98 \%$ of stillbirths occurred in low-income and middleincome countries (4). Stillbirth rate in the Middle East has ranged from 10 to 20 per 1000 births (5). In high-income countries, one in every 200 pregnancies leads to stillbirth (6). Although stillbirth rate in high-income countries has decreased, its rate remained stable or declined slightly in these countries during the past 2 decades (7).

Several conditions have been associated with stillbirth, but finding the exact etiology is often complicated (8). A large number of stillbirths could be prevented by simple interventions such as improvement of prenatal care, development, and implementation of appropriate health care policies for managing high-risk pregnancies $(9,10)$.

The prevalence of stillbirth due to unknown causes varies from $25 \%$ to $60 \%$ (10). Identifiable causes can be attributed to maternal, fetal, and placental conditions. The causes of stillbirth are different among developed and developing countries (8). Risk factors in developed countries include nulliparity, advanced maternal age, obesity, overweight, and fetal growth restriction (6), whereas prolonged and obstructed labor leading to trauma and asphyxia and various infections are the main risk factors in developing countries (11).

Stillbirth is a neglected issue and has not been prioritized in Millennium Development Goals, Sustainable Development Goals, and even in most health policies and programs (4). The global Every Newborn Action Plan (ENAP), launched in 2014, provides evidenced-based approaches for ending preventable new born mortality and stillbirth. One of ENAP goals is to decrease the stillbirth rate to 12 per 1000 births or less by 2030 worldwide (12). Therefore, the primary objective of this study was to determine stillbirth rate at the national and provincial levels in Iran. The second goal was to investigate and predict the risk factors of stillbirth to achieve the objectives of ENAP to help with programs and policies to address this burden.

In the past years, in Iran, birth information has been recorded using hand-written forms. Furthermore, the data were used only for the issuance of birth certificates and fewer hospitals utilized this data to promote maternal and neonatal health.

Since 2011, the Neonatal Health Office and Bureau of Population, Family and School Health, with the cooperation of other related offices and the vast majority of maternity and neonatal health experts in the universities, designed questionnaires and software for recording the birth events in hospitals. They launched this new system to access useful and essential information for extracting maternal and neonatal health indicators and their application for policy and health planning. The new registration system was implemented as a pilot project in some medical universities, and the deficiencies were resolved and completed gradually. Since April 2012, all the hospitals and birth centers covered by medical universities began to register the information in the Iranian Maternal and Neonatal Network (IMaN) online.

Iranian Maternal and Neonatal Network (IMaN) is one of the greatest sources of information for monitoring ma- ternal and neonatal health. This network registers almost all births (live \& dead), demographic, maternal, and neonatal health information electronically in and out of the hospital across the country. Finally, in 2014, IMaN started to register out of hospital births that happened at maternity and childbirth facilities, homes, or other places. Since then, the network has evolved and developed.

Information such as the demographic characteristics of the newborn's mother, consanguinity of parents, number of parity and gravidity, mode of delivery, abortion history, gestational weeks, mother's medical history, risk factors for pregnancy and childbirth, childbirth damage, childbirth intervention, date of birth and the baby's birth characteristics, neonatal abnormalities and stillbirth are recorded in the network. We defined stillbirth as the birth of a baby with 22 or more completed weeks of gestation who died before or during labor.

\section{Methods}

In this population-based study, data from 2014-2016 were received from the Ministry of Health and Medical Education. We identified duplicates primarily by national registration codes; for those with missing codes, we used a combination of 10 variables to detect duplicated records. About $0.4 \%$ of all recorded cases were duplicates. Outliers were verified and corrected by consulting experts at the Ministry of Health. If the data were incorrect, and there was no possibility of correction, they were considered as missing data.

Independent variables were as follow: child sex, mother's age at the time of birth, mother's history of stillbirth and abortion, mother's educational level, location of residency (urban/rural), delivery mode (vaginal/caesarian), consanguinity of parents, birth attendants, gestational age, fetus weight, hospital type (public/private), health insurance, gravidity, and some maternal diseases.

In IMaN, there was a variable called district of birth, which included all cities and towns which were birthplaces of infants. Regarding country divisions, the cities and towns of each province were manually identified and recoded into a variable called province, which included all 31 provinces in Iran. Stillbirth was considered as the dependent variable.

\section{Statistical Analysis}

Data were analyzed via IBM SPSS Statistics v 24.0. Chi-squared analysis was used to compare categorical variables when appropriate. In our analysis, stillbirth was measured as a binary variable taking the value of one or zero. We used forward stepwise logistic regression to detect factors related to stillbirth outcome. Multicollinearity was checked and factors with high multicollinearity, such as body weight at the time of delivery (fetus or neonate), were excluded from this analysis. We performed bivariate analysis, and variables with a $\mathrm{p}$ value $<0.2$ were entered into logistic regression. Adjusted odds ratios (ORs) and $95 \%$ confidence interval were obtained. A p value $<0.05$ was considered statistically significant. ArcGIS v 10.2.2 was used to create maps. We excluded such variables as history of mother's stillbirth, insurance type, congenital 
malformation, and some maternal diseases, due to missing data.

IMaN contains almost all pregnancies which have been resulted to either stillbirth or live birth. By comparing live births registered by IMan and National Organization for Civil Registration (OCR), it was obtained that IMaN coverage was $93 \%$ of the total births in 2014 and it increased by $96 \%$ in 2015 and about $97 \%$ in 2016 . According to the national laws, death certificate should be issued for every stillbirth case that occurs in hospitals.

In other words, it is a cohort of all pregnancies after the gestational age of 20 weeks; considering this fact and scarcity of stillbirth as an outcome, we believe that our OR estimates are good indicators for risk ratio.

\section{Ethical consideration}

Anonymous data for all stillborn and live births in Iran from 2014 to 2016 were obtained with permission from the Neonatal Health Office of Ministry of Health and Medical Education. The ethical issues of this study were approved in the Vice-Chancellor for Research Affairs of Faculty of Medicine, Iran University of Medical Sciences. The ethics committee code is IR.IUMS.REC 1395.95-03221-29716.

\section{Results}

Iranian Maternal and Neonatal Network (IMaN) registered 1437017 births (live \& dead) in 2014 and 1512 225 births in 2015. Total births in 2016 were 1487683 . Tehran, Khorasan Razavi, and Khuzestan had the highest births among all other provinces in Iran. In our study, stillbirth was defined as the birth of a baby with 22 or more completed weeks of gestation who died before or during labor. The number of total stillbirths in 2014, 2015, and 2016 was 10 631, 10 918, and 11 352, respectively. Figure 1 shows the average rate of stillbirth during 3 years

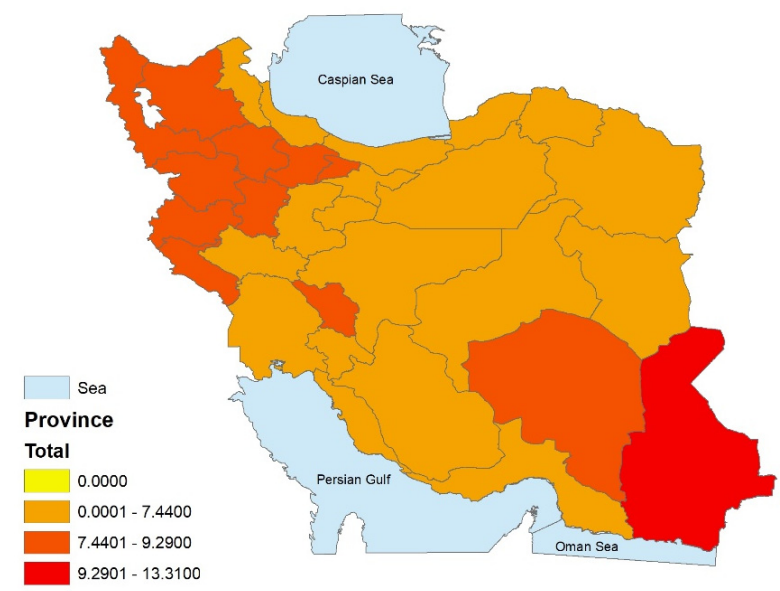

Fig. 1. Stillbirth rate per 1000 total births by province in Iran (20142016)

(2014-2016) in all the provinces of Iran. Most stillbirths occurred in the southeast and northwest of the country, with Sistan \& Baluchestan having the highest stillbirth rate.

In 2014 , still birth rate was $7.06,7.48$, and 7.40 in female, in male, and in total per 1000 births. In 2015, stillbirth rate was $6.77,7.38$, and 7.22 in female, male, and in total per 1000 births. In 2016, stillbirth rate was 7.73, 7.17, and 7.63 in male, female, and in total per 1000 births, respectively.

Appendix Table 1 illustrates the stillbirth rate of all Iran provinces from 2014 to 2016. Stillbirth occurred in approximately one out of every 142 pregnancies in 2014 , one out of every 120 pregnancies in 2015, and one out of 131 pregnancies in 2016. Appendix Figures 1 and 2 demonstrate the average stillbirth rate in male and female births in Iran (2014-2016).

Table 1 shows demographics and medical characteris-

Table 1. Demographics and medical characteristics of stillbirths and live births in Iran (2014-2016)

\begin{tabular}{|c|c|c|c|c|c|c|}
\hline & & Stillbirth & & & Live birth & \\
\hline Year & 2014 & 2015 & 2016 & 2014 & 2015 & 2016 \\
\hline Total & 10631 & 10918 & 11352 & 1426386 & 1501307 & 1476331 \\
\hline Child sex & $\mathrm{N}(\%)$ & $\mathrm{N}(\%)$ & $\mathrm{N}(\%)$ & $\mathrm{N}(\%)$ & $\mathrm{N}(\%)$ & $\mathrm{N}(\%)$ \\
\hline Male & $5543(52.1)$ & $5755(52.7)$ & $5934(52.3)$ & $735524(51.6)$ & $773057(51.5)$ & $760925(51.5)$ \\
\hline Female & $4907(46.2)$ & $4963(45.5)$ & $5169(45.5)$ & $690330(48.4)$ & $727736(48.5)$ & $714972(48.4)$ \\
\hline Ambiguous & $181(1.7)$ & $200(1.8)$ & $249(2.2)$ & $532(0.0)$ & $514(0.0)$ & $401(0.0)$ \\
\hline Mother's age & $\mathrm{N}(\%)$ & $\mathrm{N}(\%)$ & $\mathrm{N}(\%)$ & $\mathrm{N}(\%)$ & $\mathrm{N}(\%)$ & $\mathrm{N}(\%)$ \\
\hline Less than 18 years & $306(2.9)$ & $326(3.0)$ & $317(2.8)$ & $34163(2.4)$ & $33873(2.3)$ & $32705(2.2)$ \\
\hline $18-35$ & $8661(81.5)$ & $8744(80.1)$ & $9044(79.7)$ & $1244456(87.2)$ & $1296085(86.3)$ & $1263405(85.6)$ \\
\hline More than 35 years & $1664(15.7)$ & $1848(16.9)$ & 1991(17.5) & $147767(10.4)$ & $171349(11.4)$ & $180188(12.2)$ \\
\hline History of mother's stillbirth & $*$ & $*$ & $415(4.1)$ & $*$ & $*$ & $14636(1 \cdot 1)$ \\
\hline History of mother's abortion & $2299(21.6)$ & $2481(22.7)$ & $2705(23.8)$ & $228227(16.0)$ & $255115(17.0)$ & 268804(18.2) \\
\hline Mother's educational level & N (\%) & N (\%) & $\mathrm{N}(\%)$ & $\mathrm{N}(\%)$ & $\mathrm{N}(\%)$ & $\mathrm{N}(\%)$ \\
\hline Illiterate & $1228(11.6)$ & $1168(10.7)$ & $1132(10.0)$ & $100603(7.1)$ & $96412(6.4)$ & $86901(5.9)$ \\
\hline Primary school & $2255(21.2)$ & $2343(21.5)$ & 2264(19.9) & $257932(18.1)$ & $258571(17.2)$ & $239085(16.2)$ \\
\hline Guidance/high school & $5580(52.5)$ & $5732(52.5)$ & $6069(53.5)$ & $797354(55.9)$ & $840634(56.0)$ & $820745(55.6)$ \\
\hline University & $1568(14.7)$ & $1675(15.3)$ & $1887(16.6)$ & $270497(19.0)$ & $305690(20.4)$ & $329567(22.3)$ \\
\hline Location of residence & $\mathrm{N}(\%)$ & $\mathrm{N}(\%)$ & $\mathrm{N}(\%)$ & $\mathrm{N}(\%)$ & $\mathrm{N}(\%)$ & $\mathrm{N}(\%)$ \\
\hline Rural & $3168(29.8)$ & $3104(28.4)$ & $2744(24.2)$ & $379950(26.6)$ & $384654(25.6)$ & $316234(21 \cdot 4)$ \\
\hline Urban & $7463(70.2)$ & $7814(71.6)$ & $8608(75.8)$ & $1046436(73.4)$ & $1116653(74.4)$ & $1160064(78.6)$ \\
\hline Delivery type & $\mathrm{N}(\%)$ & $\mathrm{N}(\%)$ & N (\%) & $\mathrm{N}(\%)$ & $\mathrm{N}(\%)$ & $\mathrm{N}(\%)$ \\
\hline Vaginal & $8427(79.3)$ & $8631(79 \cdot 1)$ & $9005(79.3)$ & $700198(49.1)$ & $761272(50.7)$ & $736175(49.9)$ \\
\hline Caesarian & $2204(20.7)$ & $2287(20.9)$ & $2347(20.7)$ & $726188(50.9)$ & $740035(49.3)$ & $740123(50.1)$ \\
\hline Consanguinity of parents & $2786(26.2)$ & $2662(24.4)$ & $2770(24.4)$ & $321530(22.5)$ & $325449(21.7)$ & $308632(20.9)$ \\
\hline
\end{tabular}

*Data were not available.

**There were missing data in this field. 


\begin{tabular}{|c|c|c|c|c|c|c|}
\hline \multirow[b]{2}{*}{ Year } & \multicolumn{3}{|c|}{ Stillbirth } & \multicolumn{3}{|c|}{ Live birth } \\
\hline & 2014 & 2015 & 2016 & 2014 & 2015 & 2016 \\
\hline Total & 10631 & 10918 & 11352 & 1426386 & 1501307 & 1476331 \\
\hline Birth attendants & $\mathrm{N}(\%)$ & $\mathrm{N}(\%)$ & $\mathrm{N}(\%)$ & $\mathrm{N}(\%)$ & $\mathrm{N}(\%)$ & $\mathrm{N}(\%)$ \\
\hline $\begin{array}{l}\text { Skilled or Trained birth } \\
\text { attendants }\end{array}$ & 10434(99.1) & $10829(99.2)$ & $11289(99.4)$ & $1404756(99.7)$ & $1494450(99.5)$ & $1473470(99.8)$ \\
\hline Traditional birth attendants & $95(0.9)$ & $89(0.8)$ & $63(0.6)$ & $3761(0.3)$ & $6853(0.5)$ & $2828(0.2)$ \\
\hline Gestational age & $\mathrm{N}(\%)$ & $\mathrm{N}(\%)$ & N (\%) & $\mathrm{N}(\%)$ & $\mathrm{N}(\%)$ & $\mathrm{N}(\%)$ \\
\hline Preterm (22-36 weeks) & $8590(80.8)$ & $8724(79.9)$ & $9331(82.2)$ & $100050(7.0)$ & $106045(7.1)$ & $107546(7.3)$ \\
\hline Term (37-41weeks) & $2005(18.9)$ & $2159(19.8)$ & 1997(17.6) & $1320891(92.6)$ & $1389882(92.6)$ & $1364158(92.4)$ \\
\hline Post term ( $\geq 42$ weeks) & $34(0.3)$ & $32(0.3)$ & $21(0.2)$ & 4935(0.3) & 4614(0.3) & $3962(0.3)$ \\
\hline Fetus weight & $\mathrm{N}(\%)$ & $\mathrm{N}(\%)$ & $\mathrm{N}(\%)$ & $\mathrm{N}(\%)$ & $\mathrm{N}(\%)$ & $\mathrm{N}(\%)$ \\
\hline ELBW (Less than 999gr) & $5109(48.1)$ & $5153(47.2)$ & $5812(51.2)$ & $6248(0.4)$ & $6747(0.4)$ & $6452(0.4)$ \\
\hline VLBW (1000-1499gr) & $1206(11.3)$ & $1268(11.6)$ & 1261(11.1) & $7528(0.5)$ & $7511(0.5)$ & $7577(0.5)$ \\
\hline LBW (1500-2499gr) & $1937(18.2)$ & $1963(18.0)$ & $1975(17.4)$ & $83369(5.8)$ & $84562(5.6)$ & $84010(5.7)$ \\
\hline Normal (2500-4000gr) & $2237(21.0)$ & 2394(21.9) & $2165(19.1)$ & $1287241(90.2)$ & $1355224(90.3)$ & $1331657(90.2)$ \\
\hline $\begin{array}{l}\text { Macrosomia (More than } \\
4000 \mathrm{gr} \text { ) }\end{array}$ & $142(1.3)$ & $140(1.3)$ & $139(1.2)$ & $42000(2.9)$ & $47263(3.1)$ & $46602(3.2)$ \\
\hline Hospital type & $\mathrm{N}(\%)$ & $\mathrm{N}(\%)$ & N (\%) & $\mathrm{N}(\%)$ & $\mathrm{N}(\%)$ & $\mathrm{N}(\%)$ \\
\hline Public & $9695(92.1)$ & $9871(91.5)$ & 10295(91.6) & $1185872(84.2)$ & $1245769(84.3)$ & $1212829(83.2)$ \\
\hline Private & $834(7.9)$ & $915(8.5)$ & $949(8.4)$ & $222645(15.8)$ & 232713(15.7) & 244977(16.8) \\
\hline Gravidity & $\mathrm{N}(\%)$ & $\mathrm{N}(\%)$ & $\mathrm{N}(\%)$ & $\mathrm{N}(\%)$ & $\mathrm{N}(\%)$ & $\mathrm{N}(\%)$ \\
\hline 1 gravida & $4012(37.7)$ & $3863(35.4)$ & $3956(34.8)$ & $542635(38.0)$ & $529809(35.3)$ & $504316(34.2)$ \\
\hline 2-4 gravida & $5646(53.1)$ & $5992(54.9)$ & $6310(55.6)$ & $815320(57.2)$ & $894003(59.5)$ & $891656(60.4)$ \\
\hline more than 4 gravida & $973(9.2)$ & $1063(9.7)$ & $1086(9.6)$ & $68431(4.8)$ & $77495(5.2)$ & $80326(5.4)$ \\
\hline Parity & $\mathrm{N}(\%)$ & $\mathrm{N}(\%)$ & $\mathrm{N}(\%)$ & $\mathrm{N}(\%)$ & $\mathrm{N}(\%)$ & $\mathrm{N}(\%)$ \\
\hline $0-1$ & $7854(73.9)$ & $7880(72.2)$ & $8206(72.3)$ & $1128652(79.1)$ & $1165328(77.6)$ & $1134127(76.8)$ \\
\hline $2-4$ & $2469(23.2)$ & 2724(24.9) & $2872(25.3)$ & 280915(19.7) & $317628(21.2)$ & $323988(21.9)$ \\
\hline$\geq 5$ & $308(2.9)$ & $314(2.9)$ & $274(2.4)$ & $16819(1.2)$ & $18351(1.2)$ & $18183(1.2)$ \\
\hline Lack of Insurance & $1496(14.2)$ & $225(11.2)^{* *}$ & $1158(10.3)$ & $115647(8.2)$ & $23002(9.2) * *$ & $91372(6.3)$ \\
\hline Location of birth & $\mathrm{N}(\%)$ & $\mathrm{N}(\%)$ & $\mathrm{N}(\%)$ & $\mathrm{N}(\%)$ & $\mathrm{N}(\%)$ & $\mathrm{N}(\%)$ \\
\hline In hospital delivery & 10492(98.7) & $10745(98.4)$ & $11244(99.0)$ & $1407364(98.7)$ & $1477370(98.4)$ & $1457806(98.7)$ \\
\hline Out of hospital delivery & $139(1.3)$ & $173(1.6)$ & $108(1.0)$ & 19022(1.3) & 23937(1.6) & $18525(1.3)$ \\
\hline
\end{tabular}

tics of stillbirth and live births in Iran (2014-2016). Male fetuses, female fetuses, and sexual ambiguity comprised about $52 \%, 45 \%$, and $1.5 \%$ of total stillbirths in Iran. More than $20 \%$ of mothers in stillbirth group had a history of abortion. About $99 \%$ of deliveries were performed by skilled or trained birth attendants, and only $1 \%$ of deliveries were done by traditional midwives. More than $70 \%$ of dead embryos weighed less than 2500 grams. Approximately $98 \%$ of our deliveries occurred in hospitals.

Preeclampsia/eclampsia, gestational diabetes mellitus (GDM), preexisting hypertension, and thyroid disorders were the most prevalent diseases among mothers who experienced stillbirth (Table 2). There were missing variables in Table 2 because these variables were recorded by IMaN since 2016. A binominal logistic regression model was conducted to detect factors associated with stillbirth. Child sex, mother's age, history of mother's abortion, mother's educational level, location of residence, delivery type, consanguinity of parents, gestational age, birth attendants, hospital type, in hospital delivery, gestational diabetes mellitus, thyroid disease, preeclampsia/eclampsia, and pre-existing hypertension were the pre-

Table 2. History of maternal diseases of stillbirths and live births in Iran (2014-2016)

\begin{tabular}{|c|c|c|c|c|c|c|}
\hline \multirow{2}{*}{$\begin{array}{l}\text { Maternal disease } \\
\text { Year }\end{array}$} & \multicolumn{3}{|c|}{ Stillbirth } & \multicolumn{3}{|c|}{ Live birth } \\
\hline & 2014 & 2015 & 2016 & 2014 & 2015 & 2016 \\
\hline & $\mathrm{N}(\%)$ & $\mathrm{N}(\%)$ & $\mathrm{N}(\%)$ & $\mathrm{N}(\%)$ & $\mathrm{N}(\%)$ & $\mathrm{N}(\%)$ \\
\hline Total & 10631 & 10918 & 11352 & 1426386 & 1501307 & 1476331 \\
\hline Preexisting diabetes & $*$ & $*$ & $29(0 \cdot 3)$ & $*$ & $*$ & $1627(0.1)$ \\
\hline Gestational diabetes & $348(3.3)$ & $412(3.8)$ & $431(3.8)$ & $33021(2.3)$ & $38624(2.6)$ & $45586(3.1)$ \\
\hline Thyroid disorders & $186(1.7)$ & $310(2.8)$ & $507(4.5)$ & $30019(2.1)$ & $49908(3.3)$ & $74341(5.0)$ \\
\hline Anemia & $55(0.5)$ & $60(0.6)$ & $41(0.4)$ & $6100(0.4)$ & $6253(0.4)$ & $4799(0.3)$ \\
\hline Pre-existing hypertension & $247(2.3)$ & $241(2.2)$ & $235(2.1)$ & $16187(1.1)$ & $15861(1.1)$ & $15304(1.0)$ \\
\hline Preeclampsia/Eclampsia & $470(4.4)$ & $401(3.7)$ & $486(4.3)$ & 21974(1.6) & $21880(1.5)$ & $22817(1.6)$ \\
\hline Genitourinary infection & $*$ & * & $14(0.1)$ & $*$ & $*$ & $1561(0.1)$ \\
\hline Chorioamnionitis & $*$ & $*$ & $16(0.1)$ & $*$ & $*$ & $155(0.0)$ \\
\hline Smoking & $*$ & * & $3(0.0)$ & $*$ & $*$ & $233(0.0)$ \\
\hline Addiction & $*$ & $*$ & $60(0.5)$ & $*$ & $*$ & $2313(0.2)$ \\
\hline Cardiac disease & $48(0.4)$ & $75(0.7)$ & $57(0.5)$ & $7232(0.5)$ & $8016(0.5)$ & $7499(0.5)$ \\
\hline $\mathrm{HIV}+$ & $3(0.0)$ & $1(0.0)$ & $0(0.0)$ & $257(0.0)$ & $235(0.0)$ & $217(0.0)$ \\
\hline VDRL+ & $0(0.0)$ & $0(0.0)$ & $1(0.0)$ & $109(0.0)$ & $129(0.0)$ & $79(0.0)$ \\
\hline Hepatitis B & $*$ & $*$ & $15(0.1)$ & * & $*$ & $2300(0.2)$ \\
\hline Hepatitis C & $*$ & $*$ & $1(0.0)$ & $*$ & $*$ & $93(0.0)$ \\
\hline Other diseases & $527(5.0)$ & $479(4.4)$ & $356(3.2)$ & $35337(2.5)$ & $33520(2.3)$ & $28635(2.0)$ \\
\hline
\end{tabular}

*Data were not available (These variables have been recorded since 2016.). 
Table 3. Associated factors for stillbirths among total births in Iran (2014-2016)

\begin{tabular}{|c|c|c|c|c|}
\hline \multirow[t]{2}{*}{ Variables } & \multirow[t]{2}{*}{ Adjusted OR } & \multicolumn{2}{|c|}{$95 \%$ C.I. for OR } & \multirow[t]{2}{*}{$P$ value } \\
\hline & & Lower & Upper & \\
\hline \multicolumn{5}{|l|}{ Child sex } \\
\hline Male (Reference) & 1.0 & & & \\
\hline Female & 0.989 & 0.967 & 1.013 & 0.367 \\
\hline Ambiguous & 14.510 & 12.760 & 16.500 & $<0 \cdot 001$ \\
\hline \multicolumn{5}{|l|}{ Mother's age } \\
\hline $18-35$ year (Reference) & 1.0 & & & \\
\hline Less than 18 years & 0.805 & 0.751 & 0.863 & $<0.001$ \\
\hline More than 35 years & 1.393 & 1.349 & 1.438 & $<0.001$ \\
\hline History of mother's abortion & 1.239 & 1.205 & 1.274 & $<0.001$ \\
\hline \multicolumn{5}{|l|}{ Mother's educational level } \\
\hline Illiterate (Reference) & 1.0 & & & \\
\hline Primary school & 0.797 & 0.762 & 0.833 & $<0.001$ \\
\hline Guidance/high school & 0.761 & 0.730 & 0.792 & $<0.001$ \\
\hline University & 0.726 & 0.691 & 0.762 & $<0.001$ \\
\hline location of residence (Rural compared to Urban) & 0.918 & 0.893 & 0.943 & $<0.001$ \\
\hline Delivery type (Caesarian section compared to Normal Vaginal Delivery) & 0.179 & 0.174 & 0.184 & $<0.001$ \\
\hline Consanguinity of parents (Compared to non-related parents) & 1.054 & 1.025 & 1.082 & $<0.001$ \\
\hline \multicolumn{5}{|l|}{ Gestational age } \\
\hline Term (37-41 weeks) (Reference) & 1.0 & & & \\
\hline Preterm (22-36 weeks) & 62.536 & 60.777 & 64.347 & $<0 \cdot 001$ \\
\hline Post term $\geq 42$ weeks & 3.316 & 2.661 & 4.133 & $<0.001$ \\
\hline Hospital type (Private compared to Public hospital) & 1.091 & 1.043 & 1.140 & $<0.001$ \\
\hline Preexisting hypertension (compared to people with no history of hypertension) & 1.287 & 1.189 & 1.393 & $<0.001$ \\
\hline Preeclampsia/Eclampsia (compared to pregnancies without $\mathrm{PE} / \mathrm{E}$ ) & 1.211 & 1.142 & 1.283 & $<0.001$ \\
\hline Out of hospital delivery (compared to in hospital delivery) & 1.642 & 1.277 & 2.111 & $<0.001$ \\
\hline
\end{tabular}

dictors, and stillbirth was the dependent variable. All the predictors were entered as categorical variables. Because of missing data, 4452990 participants were included in the regression analysis (Table 3 ). The model explained $34.1 \%$ (Nagelkerke R2) of the variance in stillbirth and classified $99.3 \%$ of the cases correctly. The unadjusted ORs for genital ambiguity and post term were 57.34 (CI; 52.15-63.04) and 4.25 (CI; 3.44-5.26) respectively, whereas the adjusted ORs for genital ambiguity and post term were 14.51 (CI; 12.76-16.5), and 3.31 (CI; 2.66$4.13)$, respectively.

Genital ambiguity, advanced maternal age, history of maternal abortion, consanguinity of parents, preterm and post term pregnancy, pre-existing hypertension, preeclampsia/eclampsia and out of hospital delivery all were associated with stillbirth. The most important factors of stillbirth were preterm birth $(\mathrm{OR}=62.53,95 \% \mathrm{CI}$; 60.77-64.34), sexual ambiguity $(\mathrm{OR}=14.51,95 \% \mathrm{CI}$; $12.76-16.50)$, and post term birth $(\mathrm{OR}=3.31,95 \% \mathrm{CI}$; 2.66-4.13).

Appendix Table 2 shows congenital anomalies among stillbirths and live births in Iran from 2014 to 2015. Data for 2016 were not available.

\section{Discussion}

The average stillbirth rate ( $\geq 22$ weeks' gestation) was 7.42 per 1000 total births during 2014-2016 in Iran; however, at subnational level, there is still disparity to some extent. Almost all provinces (96.77\%) met ENAP target, but some provinces, such as Sistan \& Baluchestan, Alborz, Zanjan, Ilam, Hamedan, and Kermanshah, had the highest average of stillbirth rate across the country. According to the national report of health profile of Iranian rural population, the rates of stillbirth in the rural population in 1993 and 2003 were 16.4 and 13.1 per 1000 total births, respectively.

This report showed that the stillbirth rate had a decreasing trend from 1993 to 2003 in rural areas (13). Based on the global burden of disease study, the SBR was 6.82 (CI; $5.71-8.10)$ per 1000 live births in Iran in 2015 (14).

The stillbirth rate (SBR) is estimated to be 18.4 per 1000 births worldwide, based on the definition of a baby born with no signs of life at or after 28 weeks' gestation (15). SBR ( $\geq 28$ weeks' gestation) was 14.5 (uncertainty range 12.9-17.5) per 1000 births in North Africa and Middle East region in 2015. The annual rate of reduction in stillbirth rate was $2.1 \%$ from 2000 to 2015 in these regions (16). Although the rate of stillbirth in Iran is lower than the global and regional rates, variation is evident in SBR at the subnational level. This difference may be due to socioeconomic inequalities and lack of access to proper health care $(17,18)$.

Stillbirth rate varied from 13.05 per 1000 total births in Sistan \& Baluchestan to 5.38 in Mazandaran in 2016.This diversity may be explained by variation in income and women's education level in different provinces. The provinces with higher income and higher percentage of women with middle to high school education had a lower stillbirth rate $(19,20)$.

This finding was similar to the Global Burden of Disease (GBD 2015) study which demonstrates that stillbirth rates range from $6.73(5.90-7.70)$ in high-middle SDI countries to $20.56(15.95-27-02)$ in low SDI countries (14).

There was a significant association between stillbirth and location of residence (rural \& urban area); based on our study, living in rural areas is a protective factor. This may be due to the expansion of Primary Health Care (PHC) network in our country which provides free prenatal care in both rural and urban areas (21). Access to prenatal services is available for almost all women across the 
country. Some prenatal tests, vaccinations, supplements, and educational classes in pregnancy are free and covered by basic insurance. Vaginal delivery in public hospitals is free since 2014 (22).

Sexual ambiguity was more prevalent in stillbirth cases, which may be due to low gestational age and lack of sexual differentiation. Male fetuses comprised about 52\% of total stillbirths in Iran. In this study, the female sex was a protective factor, but it was not significant. A metaanalysis of 30 million births illustrated that male sex is an important risk factor for stillbirth. The risk of stillbirth is $10 \%$ higher in the male fetuses (23). In animal models, in the very early stages of life, male embryos have faster development and higher metabolism than females. These factors make the male embryos more susceptible to stressors such as endocrine alteration, oxidative stress, and nutritional deficiencies (24-26). In some studies, advanced maternal age was associated with an increased risk of fetal death (27-29). Our study showed this association too.

In multiple logistic regression analysis preterm birth enhanced fetal demise by 62.53 times (95\% CI; 60.7764.34). This observation was in line with other studies $(30,31)$.

In developed countries, $80 \%$ of all stillbirths are preterm, equivalent to $5 \%$ to $10 \%$ of all preterm births. This pattern may be higher in developing countries (32).

We found that post term pregnancy increased the risk of still birth by 3.31 times (95\% CI; 2.66-4.13). This finding was in accordance with previous reports that emphasized increasing the gestational age is associated with increased risk of stillbirth, especially after 39 weeks. Therefore, theoretically in pregnancies that are at risk of fetal demise, pregnancy termination at 39 weeks may prevent some cases of stillbirth $(27,33,34)$.

More than $95 \%$ of deliveries in our country occur in the hospital, and the public sector covers about $91 \%$ of them. Based on this study, delivery in the private sector increased the risk of stillbirth. Adams et al found that perinatal mortality rates were higher in public than in the private sector. Delivery in public hospitals increased the risk of stillbirth by 1.24 times $(95 \% \mathrm{CI} ; 0.95-1.61)$ compared to private hospitals, but it was not significant (35). There was a greater than 1.2- fold (aOR; 1.28, CI; 1.18-1.39) increase in odds for stillbirth among mothers with preexisting hypertension. Similar to our study, a population-based study illustrated that fetal death rates increased by 3.2 times $(\mathrm{CI} ; 1.9-5.4)$ in women with preexisting hypertension (36).

The Iranian comprehensive maternal health care program provides care before pregnancy and continues during the pregnancy and postpartum periods. This program provides access to primary health care providers, midwives, general practitioners, and obstetrics and gynecologist in the health care centers. This program comprises various guidelines and protocols, including guidelines about screening and diagnosis of GDM, chronic hypertension, and guideline of preeclampsia/eclampsia in pregnancy (37). Prenatal care is part of primary health care in Iran and is available in urban and rural areas. Stratification of prenatal care services is designed to improve access and quality assurance across the country (38).

According to the Sixth National Development Plan and General population policies in Iran, the government has been obliged to reduce the maternal mortality ratio by 15 per 100000 live births by 2021, and the neonatal mortality rate by 7 per 1000 live births by this year. Such policies improve availability and accessibility to high qualified prenatal care in deprived and remote areas. The Ministry of Health and Medical Education also implements the ENAP in the country (39).

Due to the implementation of these programs, maternal mortality ratio (34.8 per 100000 live births in 1990 to 23.3 per 100000 live births in 2017) and neonatal mortality rate (29.4 per 1000 live births in 1990 to 8.3 per 1000 live births in 2017) have decreased significantly (40).

There was a 1.21 -fold $(95 \% \mathrm{CI} ; 1.14-1.28)$ increase in odds for stillbirth among women who suffered from preeclampsia/eclampsia. Other studies presented that preeclampsia increased fetal demise by the odds of 1.2- to 4-fold (41-43).

In a population-based cohort study, relative risk of stillbirth at different gestational age among pregnancies diagnosed with preeclampsia were estimated. The risk of fetal death among 3037 pregnancies with preeclampsia was 11.6 per 1000 in week 26, 4.6 per 1000 in week 28 , and 2.5 per 1000 in week 32. Furthermore, preterm diagnosis of preeclampsia was associated with considerably higher risk of fetal demise (43). Since most stillbirths are associated with preeclampsia and most eclampsia are related to maternal mortality, the importance of prenatal care is manifested (44).

In our study, we benefited from a large sample size, but we had some limitations, such as high proportion of unknown or missing data in the IMaN database. Some variables, such as smoking, drug abuse, preexisting diabetes, chorioamnionitis, and history of stillbirth, were recently included in the database. These variables may have had an influence on the outcome, but due to small sample size, they were not entered in the model. In delivery rooms, some neonatal deaths may be assigned to stillbirth, but in recent years, coinciding with the implementation of IMaN, the Neonatal Health Office has conducted numerous educational programs for personnel in charge of the program in the delivery and operational rooms throughout the country to prevent the neonatal death and abortion assignment to stillbirth. According to national law, hospitals are required to issue death certificates for all cases of stillbirth, but there is a risk of underestimation in remote and deprived areas. Women in this region may not go to hospitals and a stillbirth may not be reported.

\section{Conclusion}

Due to the fact that Iran has reached the ENAP target for the stillbirth rate at the national level, it is necessary that policymakers set new targets for the rate of stillbirth at the national and provincial levels. Based on evidence, $4 \%$ annual reduction in the rate of stillbirth is recommended at the national and subnational by 2030 (45). Furthermore, our study showed that risk of stillbirth increased by sexual ambiguity, advanced maternal age, history of 
maternal abortion, consanguinity of parents, preterm and post term pregnancy, preexisting hypertension, preeclampsia/eclampsia, and out of hospital delivery. Detection of stillbirth risk factors leads to better planning for the promotion of maternal and infant health care and welfare services.

\section{Acknowledgments}

We gratefully acknowledge the Ministry of Health and Medical Education for providing data for this study, and also thank Iran University of Medical Sciences for funding this project (Project number: 95-03-221-29716).

\section{Conflict of Interests}

The authors declare that they have no competing interests.

\section{References}

1. Reeske A, Kutschmann M, Razum O, Spallek J. Stillbirth differences according to regions of origin: an analysis of the German perinatal database, 2004-2007. BMC Pregnancy Childbirth. 2011;11(1):63.

2. Kelly Y, Panico L, Bartley M, Marmot M, Nazroo J, Sacker A. Why does birthweight vary among ethnic groups in the UK? Findings from the Millennium Cohort Study. J Public Health (Oxf.). 2008;31(1):131-7.

3. Jahani MA, Akbarian Rad Z, Naghavian M, Salmanian T, Haghshenas Mojaveri M. Factors affecting stillbirth rate in the hospitals affiliated to Babol University of Medical Sciences. Iran J Neonatol. 2015;6(3):22-7.

4. Bhutta ZA, Yakoob MY, Lawn JE, Rizvi A, Friberg IK, Weissman E, et al. Stillbirths: what difference can we make and at what cost? Lancet. 2011;377(9776):1523-38.

5. Stanton C, Lawn JE, Rahman H, Wilczynska-Ketende K, Hill K. Stillbirth rates: delivering estimates in 190 countries. Lancet. 2006;367(9521):1487-94.

6. Flenady V, Middleton P, Smith GC, Duke W, Erwich JJ, Khong TY, et al. Stillbirths: the way forward in high-income countries. Lancet. 2011;377(9778):1703-17.

7. Flenady V, Koopmans L, Middleton P, Frøen JF, Smith GC, Gibbons K, et al. Major risk factors for stillbirth in high-income countries: a systematic review and meta-analysis. Lancet. 2011;377(9774):1331-40.

8. Silver RM, Varner MW, Reddy U, Goldenberg R, Pinar H, Conway $\mathrm{D}$, et al. Work-up of stillbirth: a review of the evidence. Am J Obstet. Gynecol. 2007;196(5):433-44.

9. Frøen JF, Cacciatore J, McClure EM, Kuti O, Jokhio AH, Islam M, et al. Stillbirths: why they matter. Lancet. 2011;377(9774):1353-66.

10. Da Silva FT, Gonik B, McMillan M, Keech C, Dellicour S, Bhange S, et al. Stillbirth: case definition and guidelines for data collection, analysis, and presentation of maternal immunization safety data. Vaccine. 2016;34(49):6057.

11. McClure EM, Saleem S, Pasha O, Goldenberg RL. Stillbirth in developing countries: a review of causes, risk factors and prevention strategies. J Matern-Fetal Neonatal Med. 2009;22(3):183-90.

12. WHO. Every Newborn: An action plan to end preventable newborn deaths. Geneva: World Health Organization 2014 [Available from: http://www.who.int/maternal_child_adolescent/topics/newborn/ev erynewborn-action-plan-draft.pdf.

13. Naghavi M, Jafari N, Jamshidbeygi E, Vasegh S, Azad A, Akbari M. Health profile of Iranian rural population over the years 1993 to 2003. National Report. 2005.

14. Wang H, Bhutta ZA, Coates MM, Coggeshall M, Dandona L, Diallo K, et al. Global, regional, national, and selected subnational levels of stillbirths, neonatal, infant, and under-5 mortality, 1980-2015: a systematic analysis for the Global Burden of Disease Study 2015. Lancet. 2016;388(10053):1725-74.

15. Lawn JE, Blencowe H, Waiswa P, Amouzou A, Mathers C, Hogan D, et al. Stillbirths: rates, risk factors, and acceleration towards 2030. Lancet. 2016;387(10018):587-603.

16. Blencowe H, Cousens S, Jassir FB, Say L, Chou D, Mathers C, et al. National, regional, and worldwide estimates of stillbirth rates in 2015 , with trends from 2000: a systematic analysis. Lancet Glob Health 2016;4(2):e98-e108.

17. Ha YP, Hurt LS, Tawiah-Agyemang C, Kirkwood BR, Edmond KM. Effect of socioeconomic deprivation and health service utilisation on antepartum and intrapartum stillbirth: population cohort study from rural Ghana. PLoS One. 2012;7(7):e39050.

18. Zeitlin J, Mortensen L, Prunet C, Macfarlane A, HindoriMohangoo AD, Gissler M, et al. Socioeconomic inequalities in stillbirth rates in Europe: measuring the gap using routine data from the EuroPeristat Project. BMC Pregnancy Childbirth. 2016;16(1):15.

19. Household budget survey results in urban areas of Iran in 2016: Central Bank of the Islamic Republic of Iran; 2017 [Available from: https://www.cbi.ir/page/16734.aspx.

20. Iran STEPS 2016 [cited 201821 December]. Available from: https://vizit.report/panel/steps/en/main.html\#/radar

21. Mehrdad R. Health system in Iran. JMAJ. 2009;52(1):69-73.

22. Neinavaei M, Jamaledin Tabibi S, Raeissi P, Ashkan Nasiripour A. A Comparative Study of Maternity Care Service Models among Selected Developed Countries and Iran. Eur Online J Natural Soc Sci. 2015;4(1 (s)):pp. 732-40.

23. Mondal D, Galloway TS, Bailey TC, Mathews F. Elevated risk of stillbirth in males: systematic review and meta-analysis of more than 30 million births. BMC Med. 2014;12(1):220.

24. Ao A, Erickson RP, Winston RM, Handysude AH. Transcription of paternal Y-linked genes in the human zygote as early as the pronucleate stage. Zygote. 1994;2(4):281-7.

25. Tiffin G, Rieger D, Betteridge K, Yadav B, King W. Glucose and glutamine metabolism in pre-attachment cattle embryos in relation to sex and stage of development. J Reprod Fert. 1991;93(1):125-32.

26. Mao J, Zhang X, Sieli PT, Falduto MT, Torres KE, Rosenfeld CS Contrasting effects of different maternal diets on sexually dimorphic gene expression in the murine placenta. Proc Natl Acad Sci USA.

2010;107(12):5557-62.

27. Sutan R, Campbell D, Prescott G, Smith W. The risk factors for unexplained antepartum stillbirths in Scotland, 1994 to 2003. J Perinatol. 2010;30(5):311.

28. Fretts RC, Usher RH. Causes of fetal death in women of advanced maternal age. Obstet Gynecol. 1997;89(1):40-5.

29. Fretts RC, Schmittdiel J, McLean FH, Usher RH, Goldman MB. Increased maternal age and the risk of fetal death. N Engl J Med. 1995;333(15):953-7.

30. Lawn JE, Gravett MG, Nunes TM, Rubens CE, Stanton CJBp, childbirth. Global report on preterm birth and stillbirth (1 of 7): definitions, description of the burden and opportunities to improve data. BMC Pregnancy Childbirth. 2010;10(1):S1.

31. Joseph K, Demissie K, Kramer MS, editors. Obstetric intervention, stillbirth, and preterm birth. Seminars in perinatology; 2002: Elsevier.

32. Blencowe H, Cousens S, Chou D, Oestergaard M, Say L, Moller A$\mathrm{B}$, et al. Born too soon: the global epidemiology of 15 million preterm births. Reprod Health. 2013;10(1):S2.

33. Cotzias CS, Paterson-Brown S, Fisk NM. Prospective risk of unexplained stillbirth in singleton pregnancies at term: population based analysis. BMJ. 1999;319(7205):287-8.

34. Yudkin P, Wood L, Redman C. Risk of unexplained stillbirth at different gestational ages. Lancet. 1987;329(8543):1192-4.

35. Adams N, Tudehope D, Gibbons KS, Flenady V. Perinatal mortality disparities between public care and private obstetrician-led care: a propensity score analysis. BJOG. 2018;125(2):149-58.

36. Allen VM, Joseph K, Murphy KE, Magee LA, Ohlsson AJBp, childbirth. The effect of hypertensive disorders in pregnancy on small for gestational age and stillbirth: a population based study. BMC Pregnancy Childbirth. 2004;4(1):17.

37. Kharaghani R, Shariati M, Yunesian M, Keramat A, Moghisi A. The Iranian Integrated Maternal Health Care Guideline Based on Evidence-Based Medicine and American Guidelines: A Comparative Study. Modern Care J. 2016;13(2).

38. Parsa P, Shobeiri F, Parsa N. Effect of prenatal health care on pregnancy outcomes in Hamadan. Iran J Commun Med Health Edu. 2012;2(114):1-3

39. Sixth National Development Plan [cited 201822 December] Available from: www.rrk.ir/Files/Laws.

40. IHME. Health-related SDGs 2017 [Available from: https://vizhub. healthdata.org/sdg/.

41. Fretts RC. Etiology and prevention of stillbirth. Am J Obstet Gynecol. 2005;193(6):1923-35. 
Stillbirth in Iran

42. Reddy UM, Laughon SK, Sun L, Troendle J, Willinger M, Zhang J. Prepregnancy risk factors for antepartum stillbirth in the United States. Obstet Gynecol. 2010;116(5):1119.

43. Harmon QE, Huang L, Umbach DM, Klungsøyr K, Engel SM, Magnus P, et al. Risk of fetal death with preeclampsia. Obstet Gynecol. 2015;125(3):628.

44. Goldenberg R, McClure E. Importance of prenatal care in reducing stillbirth. BJOG. 2018;125(2):148-

45. Ending Preventable Stillbirths. An Executive Summary for The Lancet's Series January, 2016 [Available from: http://www.thelancet. $\mathrm{com} / \mathrm{pb} / \mathrm{assets} / \mathrm{raw} /$ Lancet/stories/series/stillbirths2016-exec-summ.pdf. 


\begin{tabular}{|c|c|c|c|}
\hline \multirow[b]{2}{*}{ Province } & \multicolumn{3}{|c|}{ Stillbirth Rate } \\
\hline & 2014 & 2015 & 2016 \\
\hline Alborz & 9.68 & 9.12 & 9.10 \\
\hline Ardebil & 7.16 & 7.53 & 6.43 \\
\hline Azarbayjan, E & 7.79 & 7.77 & 8.03 \\
\hline Azarbayjan, W & 7.72 & 8.25 & 7.26 \\
\hline Boushehr & 7.38 & 6.27 & 6.60 \\
\hline Charmahal \& Bakhtiyari & 6.64 & 7.01 & 9.29 \\
\hline Fars & 5.36 & 6.23 & 7.91 \\
\hline Ghazvin & 6.96 & 8.49 & 8.90 \\
\hline Ghom & 4.58 & 5.08 & 5.76 \\
\hline Gilan & 6.24 & 6.36 & 6.37 \\
\hline Golestan & 5.85 & 6.31 & 7.43 \\
\hline Hamedan & 9.22 & 8.46 & 8.44 \\
\hline Hormozgan & 6.98 & 7.43 & 6.76 \\
\hline Ilam & 10.13 & 9.07 & 6.98 \\
\hline Isfahan & 6.25 & 5.26 & 5.86 \\
\hline Kerman & 8.35 & 7.95 & 8.95 \\
\hline Kermanshah & 9.00 & 8.09 & 9.02 \\
\hline Khuzestan & 7.00 & 6.46 & 6.70 \\
\hline Khorasan, north & 5.38 & 6.07 & 7.93 \\
\hline Khorasan, Razavi & 6.52 & 6.71 & 7.19 \\
\hline Khorasan, south & 7.40 & 6.85 & 6.31 \\
\hline Kohkilooye \& Boyerahmad & 6.90 & 7.02 & 7.24 \\
\hline Kordestan & 8.44 & 8.61 & 8.29 \\
\hline Lorestan & 6.64 & 7.36 & 7.67 \\
\hline Markazi & 7.61 & 7.99 & 6.68 \\
\hline Mazandaran & 5.31 & 5.31 & 5.38 \\
\hline Semnan & 7.13 & 5.28 & 6.74 \\
\hline Sistan \& Baloochestan & 14.17 & 12.79 & 13.05 \\
\hline Tehran & 7.17 & 6.29 & 7.17 \\
\hline Yazd & 7.31 & 7.02 & 7.49 \\
\hline Zanjan & 9.18 & 9.87 & 8.66 \\
\hline Total & 7.40 & 7.22 & 7.63 \\
\hline
\end{tabular}

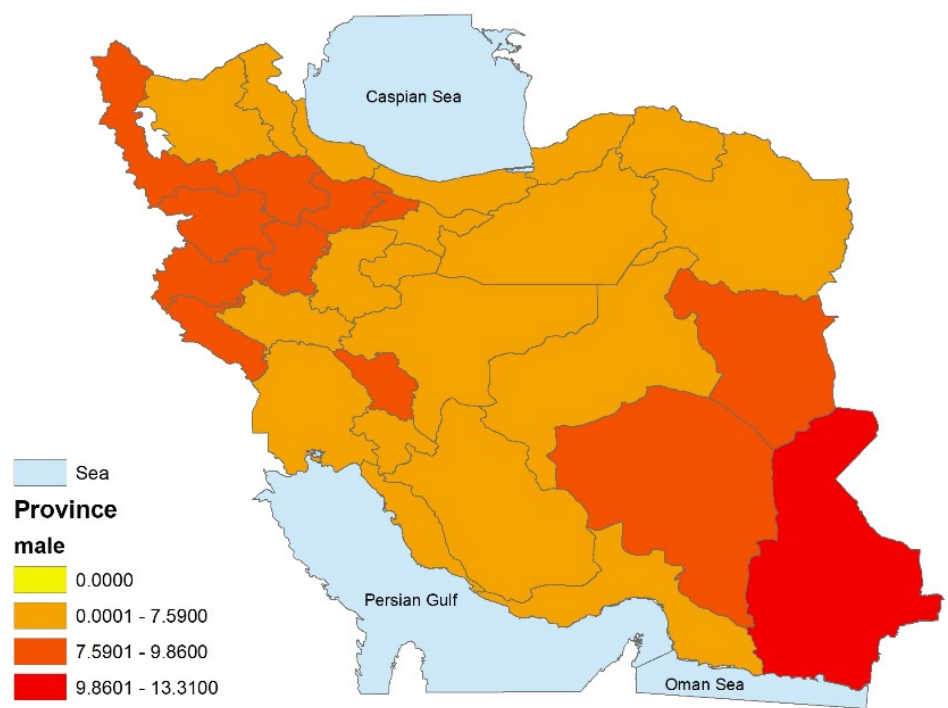

Appendix Figure 1. Stillbirth rate per 1000 total births for male by provinces of Iran (2014-2016) 


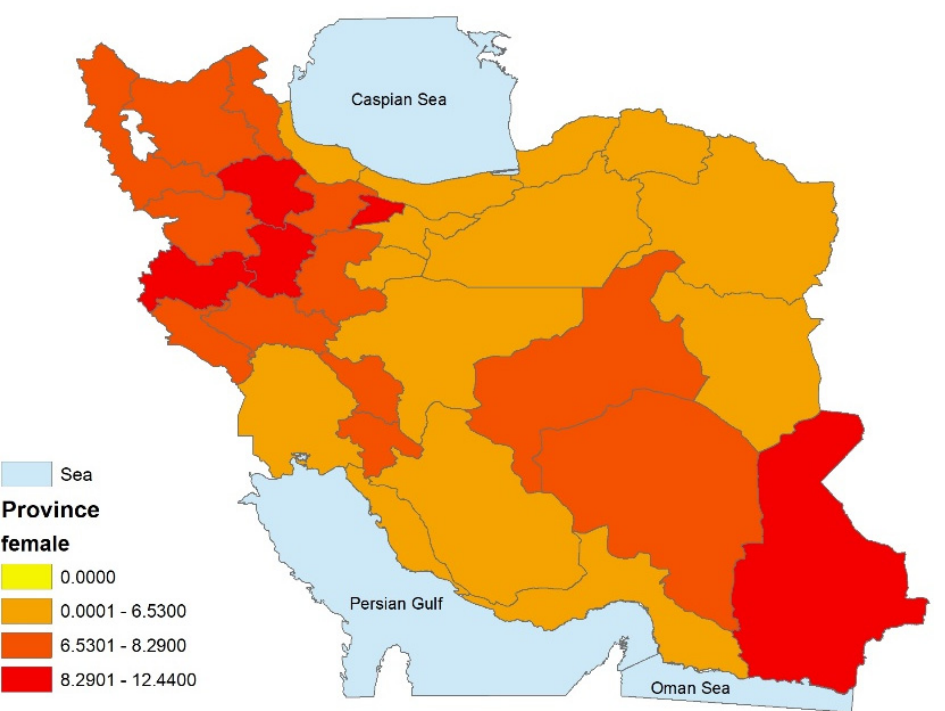

Appendix Figure 2. Stillbirth rate per 1000 total births for female by provinces of Iran (2014-2016)

Appendix Table 2. Congenital anomalies of stillbirth and live birth in Iran (2014-2015)

\begin{tabular}{lcccc}
\hline & \multicolumn{2}{c}{ Stillbirth } & \multicolumn{2}{c}{ Live birth } \\
\hline Year & 2014 & 2015 & 2014 & 2015 \\
& $\mathrm{~N}(\%)$ & $\mathrm{N}(\%)$ & $\mathrm{N}(\%)$ & $\mathrm{N}(\%)$ \\
Neural tube defect & $130(1.2)$ & $122(1.1)$ & $453(0.0)$ & $379(0.0)$ \\
Other malformation of neural tube & $156(1.5)$ & $133(1.2)$ & $480(0.0)$ & $385(0.0)$ \\
Kidney and Genitourinary & $86(0.8)$ & $91(0.8)$ & $1102(0.1)$ & $1081(0.1)$ \\
Hand \& Foot & $152(1.4)$ & $143(1.3)$ & $2612(0.2)$ & $2420(0.2)$ \\
Down syndrome & $63(0.6)$ & $33(0.3)$ & $303(0.0)$ & $263(0.0)$ \\
Other chromosomal malformation & $73(0.7)$ & $75(0.7)$ & $195(0.0)$ & $157(0.0)$ \\
Cleft palate/Cleft lip & $67(0.6)$ & $61(0.6)$ & $758(0.1)$ & $723(0.0)$ \\
Cardiovascular & $49(0.5)$ & $54(0.5)$ & $380(0.0)$ & $285(0.0)$ \\
Musculoskeletal & $70(0.7)$ & $56(0.5)$ & $380(0.0)$ & $414(0.0)$ \\
Gastrointestinal & $99(0.9)$ & $88(0.8)$ & $429(0.0)$ & $816(0.0)$ \\
Ear \& Eye & $46(0.4)$ & $43(0.4)$ & $355(0.0)$ & $655(0.0)$ \\
Face \& Neck & $129(1.2)$ & $123(1.1)$ & $440(0.0)$ & $464(0.0)$ \\
Other malformation & $717(6.7)$ & $708(6.5)$ & $1189(0.1)$ & $1257(0.1)$ \\
\hline
\end{tabular}

